medRxiv preprint doi: https://doi.org/10.1101/2022.02.01.22270236; this version posted February 1,2022 . The copyright holder for this preprint (which was not certified by peer review) is the author/funder, who has granted medRxiv a license to display the preprint in It is made available under a CC-BY-NC 4.0 International license.

\title{
Variation in English Covid booster uptake
}

\section{Greg Dropkin}

\begin{abstract}
Introduction: Variable and low takeup of the Covid booster is a recognised problem, associated with age, gender, ethnicity, and deprivation. Are there other relevant predictors?
\end{abstract}

Methods: Data was downloaded from the UK Government Coronavirus Dashboard for Middle Super Output Areas in England, along with demographic, employment, and health data from public sources. Mixed models with a random factor for Upper Tier Local Authority were analysed as quasibinomial Generalized Additive Models, and the estimated random factors were then fitted with Bayesian linear mixed models using flu vaccination uptake, change in public health budgets, vaccination centres, and Region.

Results: Models for the MSOA Covid $1^{\text {st }}$ and $2^{\text {nd }}$ vaccinations and the $3^{\text {rd }}$ injection (including the booster), fit the data well. Index of Multiple Deprivation, proportion Aged 15-24 and 25-44, and ethnicity groupings Other White, Indian-Pakistani-Bangladeshi, and African-Caribbean-Other, are highly significant predictors of lower uptake. The estimated random factors vary widely amongst local authorities, and can be predicted by flu vaccine uptake, rise in public health budgets, and regional effects which are positive for London and South East, and negative for North West and North East. Vaccination centres did not reach 90\% significance.

Discussion: Covid vaccination rates at each stage are very well modelled if local authority random effects are included along with non-linear terms for demographic, employment and health data. Deprivation, younger age, and Other White, South Asian, and Afro-Caribbean ethnicities are associated with lower uptake. Modelling the local effects indicates that increasing public health budgets would improve vaccination uptake. 
medRxiv preprint doi: https://doi.org/10.1101/2022.02.01.22270236; this version posted February 1, 2022. The copyright holder for this preprint (which was not certified by peer review) is the author/funder, who has granted medRxiv a license to display the preprint in

It is made available under a CC-BY-NC 4.0 International license .

\section{Introduction}

The booster programme has been central to the UK government's strategy for containing Covid-19 in England during the autumn and winter of 2021-22. ${ }^{1}$ However, takeup of the booster remains well below the levels achieved for the first and second vaccine doses. ${ }^{2}$ Vaccination uptake is highly dependent on age, gender, ethnicity, and deprivation, as is widely recognised 3456789

Demography varies across England, so vaccination rates will also vary. For example, as the Omicron variant swept the country on 4 January, the cumulative Third Injection (Booster or $3^{\text {rd }}$ primary) uptake in Newham was $27.2 \%$, in contrast with $41.1 \%$ in Liverpool and $67.4 \%$ in Gloucestershire. These are different populations, but does demography explain the disparity in full? If there are additional sources of variation, are they characteristics of people or of where they live?

I explore these questions by modelling cumulative Covid vaccination in 6789 Middle Super Output Areas of England, each comprising around 8,000 people on average. The models use demographic, employment and health data at MSOA level and random effects for the 149 Upper Tier Local Authorities. The resulting estimated random effects are then modelled with selected predictors available at UTLA level: Region, flu vaccination rate, the number of vaccination centres, and annual change in local authority public health budgets. Regional disparity, public experience and attitudes to vaccination in general, access to Covid-19 vaccines, and public health department capacity, are all plausible influences on how local authorities may differ even while controlling for other factors.

\section{Data sources}

The cumulative number of persons vaccinated, separately for each of two doses and the Third Injection, is available daily at MSOA level from the UK Coronavirus Dashboard ${ }^{10}$ along with the Vaccine Register Population. The Third Injection comprises people given the Booster plus people over 12 with severely weakened immune system given a $3^{\text {rd }}$ (primary) dose. The Dashboard also provides MSOA incidence ("7 day rolling rate") of Covid cases, weekly through to 5 days before download. Dashboard data was downloaded on 4 January 2022.

The Index of Multiple Deprivation (IMD), and separate indices for the Health and Education deprivation domains, were taken from the English indices of deprivation $2019^{11}$ using File 7: all ranks, deciles and scores for the indices of deprivation, and population denominators. Lower Super Output Area population and area (mid-2019 estimates) ${ }^{12}$ were used to obtain density at MSOA level. Population by MSOA was taken from the mid-2019 estimates ${ }^{13}$ which include data by gender and each year of age. Ethnicity at MSOA level from the 2011 Census was downloaded from NOMIS for the dataset DC2101EW - Ethnic group by sex by age ${ }^{14}$. Employment by industrial sector is available at MSOA level from the 2011 Census and was downloaded from NOMIS dataset DC6110EW ${ }^{15}$. Communal establishments data is available at MSOA level from the 2011 Census and was downloaded from NOMIS dataset QS421EW ${ }^{16}$. Multi-occupation housing is available at MSOA level from the 2011 Census and was downloaded from NOMIS dataset DC1109EW ${ }^{17}$.

Mean distance to GP, Emergency Department, and Pharmacy is available at LSOA level from the AHAH dataset ${ }^{18}$. GP registration mapped to LSOA is available from NHS Digital ${ }^{19}$. A lookup from MSOA to Local Authority to Upper Tier Local Authority to Region was available from Public Health England as part of weekly surveillance. The 28 October 2020 report is online, with lookup in columns 1-8 (select all, show columns) ${ }^{20}$. 
medRxiv preprint doi: https://doi.org/10.1101/2022.02.01.22270236; this version posted February 1 , 2022. The copyright holder for this preprint (which was not certified by peer review) is the author/funder, who has granted medRxiv a license to display the preprint in

It is made available under a CC-BY-NC 4.0 International license .

Seasonal Flu Vaccine Uptake data for 2020/21 was released by Public Health England ${ }^{21}$. Data was extracted for GP-registered patients aged under 65, by Local Authority. The uptake for "Leicester and Rutland" was then assigned to each area separately. Covid-19 Vaccination Centres as of 17 November 2021 were listed by NHS England ${ }^{22}$. Their postcodes were mapped to LTLA codes with the ONS National Statistics Postcode Lookup ${ }^{23}$, and then to UTLA codes via the lookup above. Public Health ring-fenced grant allocations for 2020/21 and 2021/22 are available from the Department of Health ${ }^{24}$.

\section{Statistical method and models}

The first stage of modelling seeks to explain the observed vaccination rates in terms of demographic, employment and health data at MSOA level along with random effects for the 149 UTLA.

Separately for each of three vaccinations, cumulative numbers of persons vaccinated were combined with the Vaccine Register Population to form a matrix vmat with the numbers vaccinated and unvaccinated in each of 6789 MSOA, as of 4 January 2022. For each vaccination, the corresponding matrix (vmat1 etc) is the response variable. Four models were considered, differing in the choice of explanatory covariates, and fitted separately for each vaccination.

The first stage models were structured as Generalized Additive Models, using the R package "mgcv" 2526 . The factor utla with 149 levels denotes the UTLA for each MSOA, and is treated as a random effect. All other covariates are treated as fixed effects.

Covariates for IMD, cumulative incidence, and population density were scaled. Most other covariates were transformed to improve performance. For a covariate $\mathbf{v}$, the monotonic transform $\mathbf{L V}$ is defined as $\log (1+\mathbf{v} /$ mean $(\mathbf{v}))$. For example, the population proportion for a particular ethnicity or industrial sector may be very low, but its transformation will be more easily smoothed.

The random effect smoother has the form s(utla, bs="re") whilst other smoothers have the form s(v, $\mathrm{bs}=$ "cr", $\mathrm{k}=7$ ) using cubic regression splines with basis dimension 7. Simplifying the notation from IMD onwards, the first model is

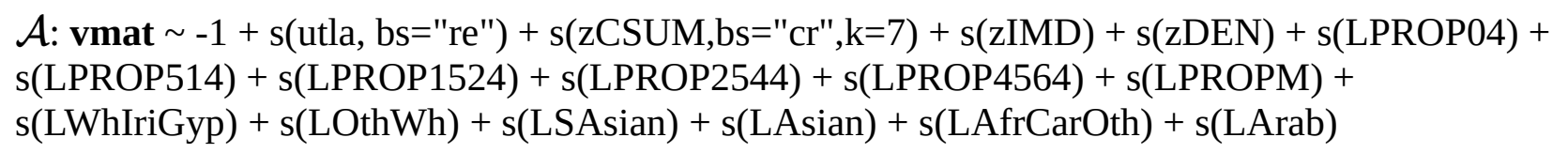

This model uses the random factor utla, cumulative incidence, IMD, population density, five age bands (as transformed proportions), male (transformed proportion), and six ethnicities (transformed proportion). The latter, using the designations from the 2011 Census, are White Irish and White Gypsy (combined group); Other White; Indian, Pakistani, and Bangladeshi (combined group); Chinese and Other Asian (combined group); African, Caribbean, Other Black, and Other Ethnicity (combined group); Arab. The initial -1 removes the intercept so that all levels of utla are treated equally.

Model $\mathcal{B}$ enlarges $\mathcal{A}$ with additional terms for the transformed population proportions of 15 industrial sectors (Agriculture Energy Water, Manufacturing, ... , Other)

$\mathcal{B}=\mathcal{A}+\mathrm{s}($ LAgEnWat $)+\ldots+\mathrm{s}($ LOther $)$ 
medRxiv preprint doi: https://doi.org/10.1101/2022.02.01.22270236; this version posted February 1, 2022. The copyright holder for this preprint (which was not certified by peer review) is the author/funder, who has granted medRxiv a license to display the preprint in It is made available under a CC-BY-NC 4.0 International license .

Model $\mathcal{C}$ enlarges $\mathcal{A}$ with additional demographic and local health covariates for Communal establishments, multi-occupation housing, population weighted mean distance to GP, to A\&E, to Pharmacy, proportion registered with GP, Health deprivation, and Education deprivation

$\mathcal{C}=\mathcal{A}+\mathrm{s}($ LCommun $)+\mathrm{s}($ LHous $)+\mathrm{s}($ LGPW $)+\mathrm{s}(\mathrm{LEDW})+\mathrm{s}($ LPHMW $)+\mathrm{s}(\mathrm{GPR})+\mathrm{s}(\mathrm{IMDH})+\mathrm{s}(\mathrm{IMDE})$

Model $\mathcal{D}$ enlarges $\mathcal{A}$ with most of the additional terms from $\mathcal{B}$ and $\mathcal{C}$, but omits six terms whose contributions showed negligible or low significance: Density, Manufacturing, Accommodation and Food, Information and Communication, Real Estate, mean distance to GP.

Models were fitted separately for each vaccination, using the quasibinomial family with smoothing parameter optimisation by marginal likelihood (method = "ML"). ${ }^{27}$ The output includes the fitted model coefficients $b$ and their Bayesian posterior covariance matrix $V_{c}$ which includes correction for smoothing parameter uncertainty (an option with the "ML" method). Model fit was evaluated with gam.check, and outliers detected by cooks.distance $>0.02$, a somewhat arbitrary criterion. The actual and predicted proportions vaccinated in each MSOA were plotted, along with the smoother curves for particular covariates. Models were compared by ML value (lower value indicates better fit).

For each fitted model, the first 149 coefficients $C_{i}$ are the estimated contributions of the levels of utla. Each $\mathrm{c}_{\mathrm{i}}$ has a standard error $\mathrm{se}_{\mathrm{i}}$, obtained as the square root of the $\mathrm{i}^{\text {th }}$ diagonal term of $V_{c}$. "Caterpillar plots" were drawn using the $\mathrm{c}_{\mathrm{i}}$ and $\mathrm{se}_{\mathrm{i}}$ to show the variation in estimated random effects.

These coefficients also enable comparison of the fitted value for a particular MSOA, with the hypothetical fitted value if the same population were located in a different UTLA, replacing $c_{i}$ with $\mathrm{c}_{\mathrm{j}}$. If $\mathrm{g}$ denotes the (quasi) binomial link $\mathrm{g}(\mathrm{p})=\log (\mathrm{p} /(1-\mathrm{p}))$ and $\mathrm{h}$ is the inverse $\operatorname{link} \mathrm{h}(\mathrm{t})=$ $1 /(1+\exp (-t))$, the fitted value would be altered from fit ${ }_{1}$ to $h\left(g\left(f_{i t}\right)-c_{i}+c_{j}\right)$.

In a second stage of modelling, the $\mathrm{c}_{\mathrm{i}}$ were taken as observed, to be predicted using covariates available for Upper Tier Local Authorities. Region was treated as a random effect, with fixed effects for the uptake of Flu vaccination, the change in Public Health ring-fenced grant allocations from 2020-21 to 2021-22, and the number of Covid Vaccination Centres within the local authority.

This stage used the Bayesian programme rstanarm ${ }^{28}$ to obtain parameter estimates and credible intervals, and a plot of predicted and observed $c_{i}$. Using the associated package "loo" ${ }^{29}$, a pointwise value of pareto_k $>0.7$ was taken to indicate an outlier. ${ }^{30}$ A Bayesian version of $R^{2}$ is used to describe overall model fit. ${ }^{31}$

In fact the $\mathrm{c}_{\mathrm{i}}$ are not observed, but are an output of first stage modelling with associated standard errors. To estimate the impact of this uncertainty, simulated $\mathbf{c}^{*}$ were drawn as multivariate normal with mean $\mathbf{c}$ (the vector with components $\mathrm{c}_{\mathrm{i}}$ ) and variance $V_{c}$. Second stage modelling was repeated using the simulated $\mathbf{c}^{*}$ to give fresh sampling output (4000 rows), and this process was repeated 100 times to produce a combined sampling matrix with 404,000 rows (including the original output from second stage modelling of the $c_{i}$ ). The mean, $5 \%$ and $95 \%$ quantiles of its columns were taken as corrected estimates and credible intervals of the second stage parameters, taking into account the uncertainty in the $\mathrm{c}_{\mathrm{i}}$. 
medRxiv preprint doi: https://doi.org/10.1101/2022.02.01.22270236; this version posted February 1, 2022. The copyright holder for this preprint (which was not certified by peer review) is the author/funder, who has granted medRxiv a license to display the preprint in

It is made available under a CC-BY-NC 4.0 International license.

\section{Results}

ML values and proportion of Deviance explained for the 4 models and 3 doses are shown in Table 1

\begin{tabular}{llll} 
Table 1: & \multicolumn{3}{c}{ value and proportion of Deviance explained } \\
Model & Dose 1 & Dose 2 & $\mathbf{3}^{\text {rd }}$ Injection \\
$\mathcal{A}$ & $-15385.47(0.954)$ & $-15974.68(0.959)$ & $-15669.84(0.965)$ \\
$\mathcal{B}$ & $-15743.80(0.959)$ & $-16259.34(0.963)$ & $-16066.13(0.970)$ \\
$\mathcal{C}$ & $-16032.83(0.962)$ & $-16560.01(0.966)$ & $-16031.49(0.969)$ \\
$\mathcal{D}$ & $-16243.52(0.965)$ & $-16746.87(0.968)$ & $-16278.81(0.972)$
\end{tabular}

The fitted models pass gam.check. For each vaccination, $\mathcal{D}$ has the lowest ML value and the highest proportion of Deviance explained.

For the $3^{\text {rd }}$ Injection with model $\mathcal{D}$, all predictors have highly significant effects $(\mathrm{p}<0.001)$ except for distance to pharmacy ( $\mathrm{p}<0.01$ ). $\mathcal{D}$ explains $97.2 \%$ of the deviance, whilst a model using only the random effects term explains 51.5\%, and a model using only the fixed effects explains $95.7 \%$ (percentages do not sum to $97.2 \%$ as in the absence of some smoothers, others compensate). Both of the reduced models have considerably worse fit than $\mathcal{D}$ (higher ML values), and are far inferior by anova tests.

Charts were produced for the $3^{\text {rd }}$ Injection with model $\mathcal{D}$.

Chart 1 shows the observed and fitted values of uptake, the outliers with cooks.distance $>0.02$ and the 37 MSOA within Newham.

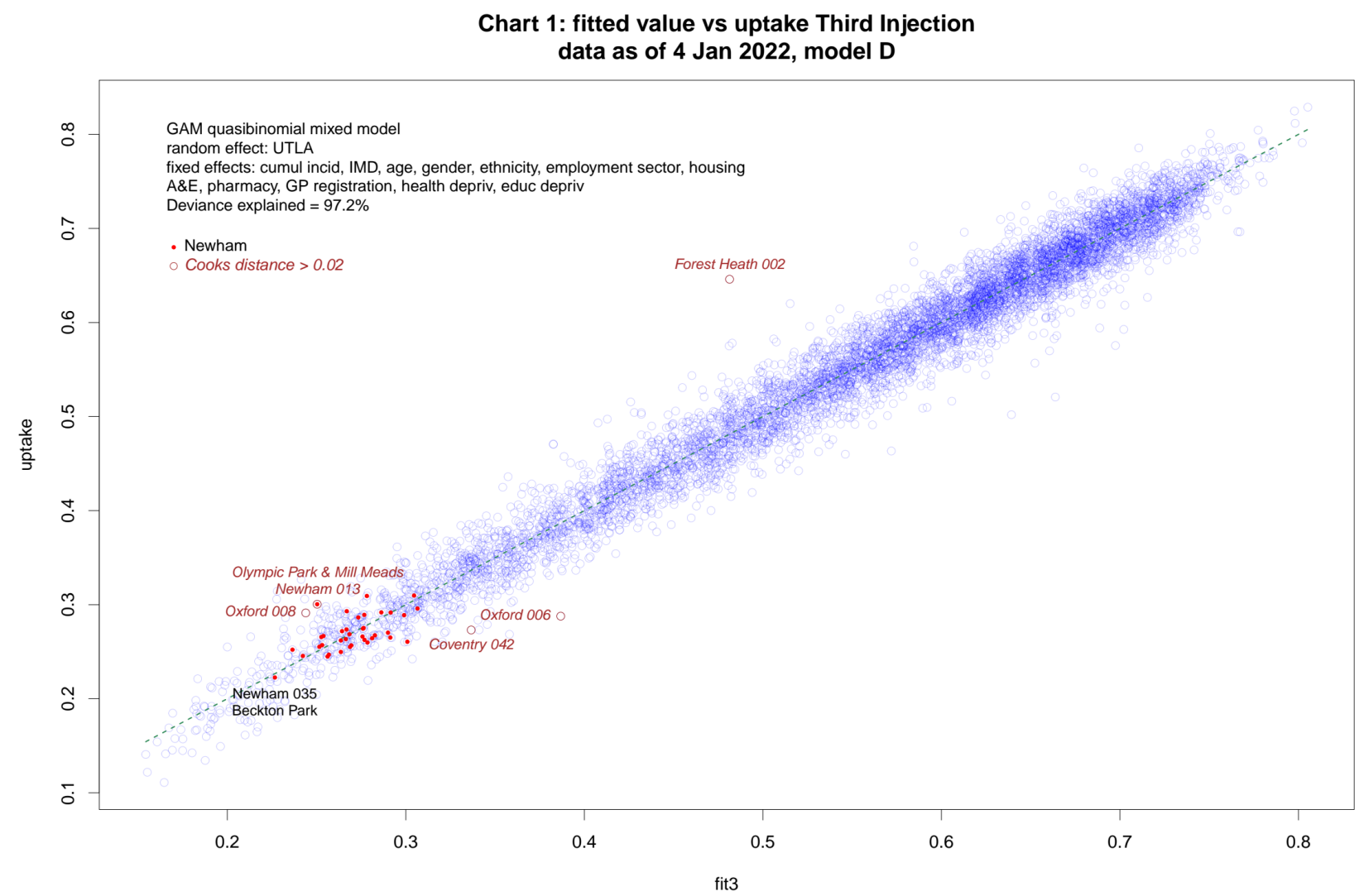

Cooks distance is a metric combining the influence of individual points on the fitted model, and the magnitude of their deviance residual. There are only five outliers as judged by cooks.distance > 0.02, and of these only Forest Heath 002 (Lakenheath) has a high residual, the others being highly influential points. Newham 013 (Olympic Park \& Mill Meads) is an outlier, with uptake higher than 
medRxiv preprint doi: https://doi.org/10.1101/2022.02.01.22270236; this version posted February 1, 2022. The copyright holder for this preprint (which was not certified by peer review) is the author/funder, who has granted medRxiv a license to display the preprint in

It is made available under a CC-BY-NC 4.0 International license .

expected. Newham 035 (Beckton Park), with the lowest uptake (0.223) in this local authority, nearly matches its predicted value (0.227). Overall, the model fits the data very well.

Chart 2 shows selected smoothers. These plot the modelled impact of individual covariates on the overall fitted value (displayed on the scale of the linear predictor, before it is translated to fitted output by the inverse link function). The $\mathrm{x}$-axis is limited by the 0.01 and 0.99 quantiles of the covariate. The first 6 smoothers shown have much larger impact on fitted values, and each of them has a negative effect: higher values of scaled IMD give lower fitted values, and likewise for the age bands and ethnicities shown. In the subsequent panels the y-axis is limited by the range of the smoother and is labelled "narrow scale". Thus an increasing male proportion also has a negative impact, but its effect is smaller than that of IMD, age, or ethnicity.
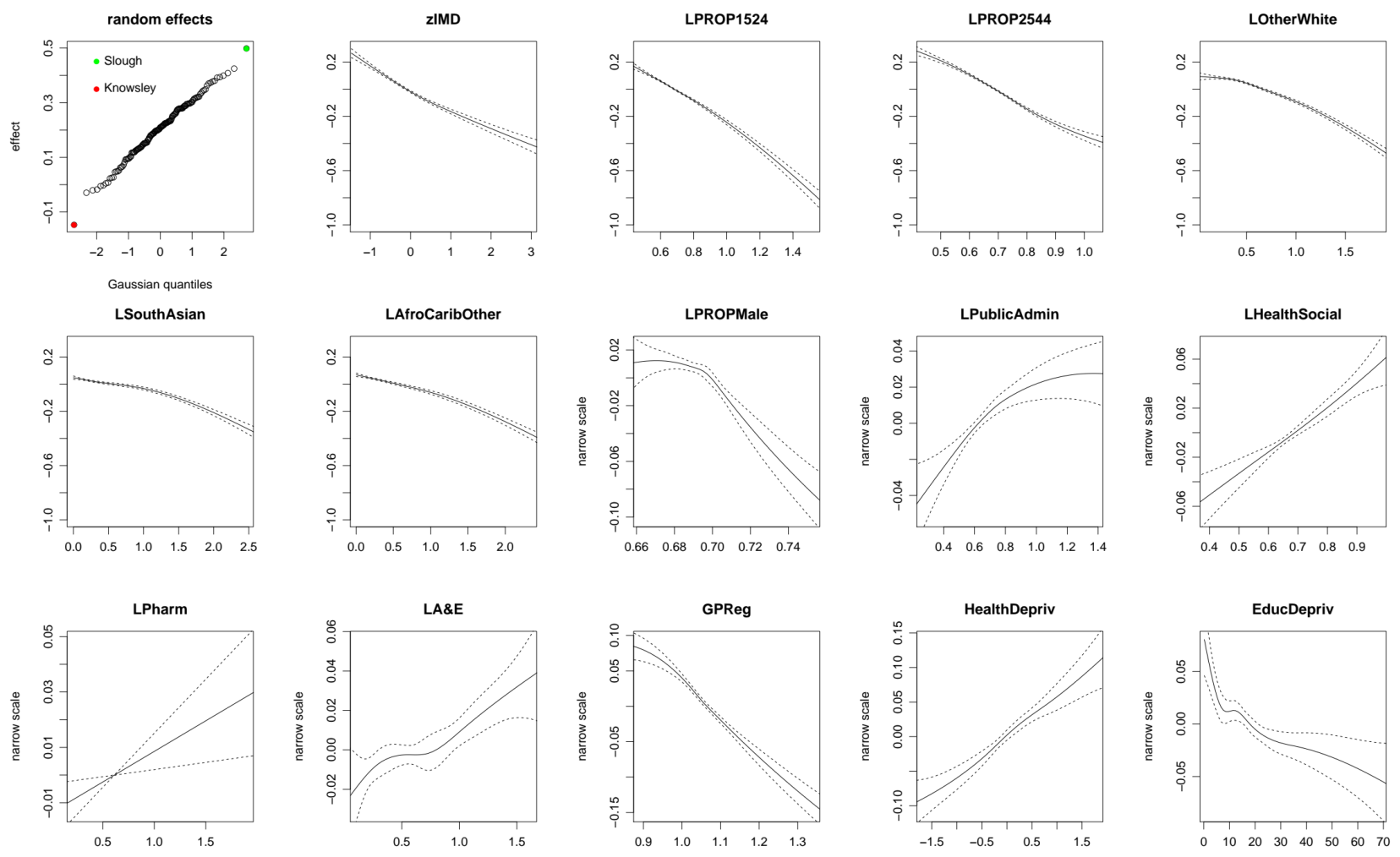

Chart 3 shows the "Caterpillar plot” for the estimated random effects. 
medRxiv preprint doi: https://doi.org/10.1101/2022.02.01.22270236; this version posted February 1 , 2022. The copyright holder for this preprint (which was not certified by peer review) is the author/funder, who has granted medRxiv a license to display the preprint in perpetuity

It is made available under a CC-BY-NC 4.0 International license .

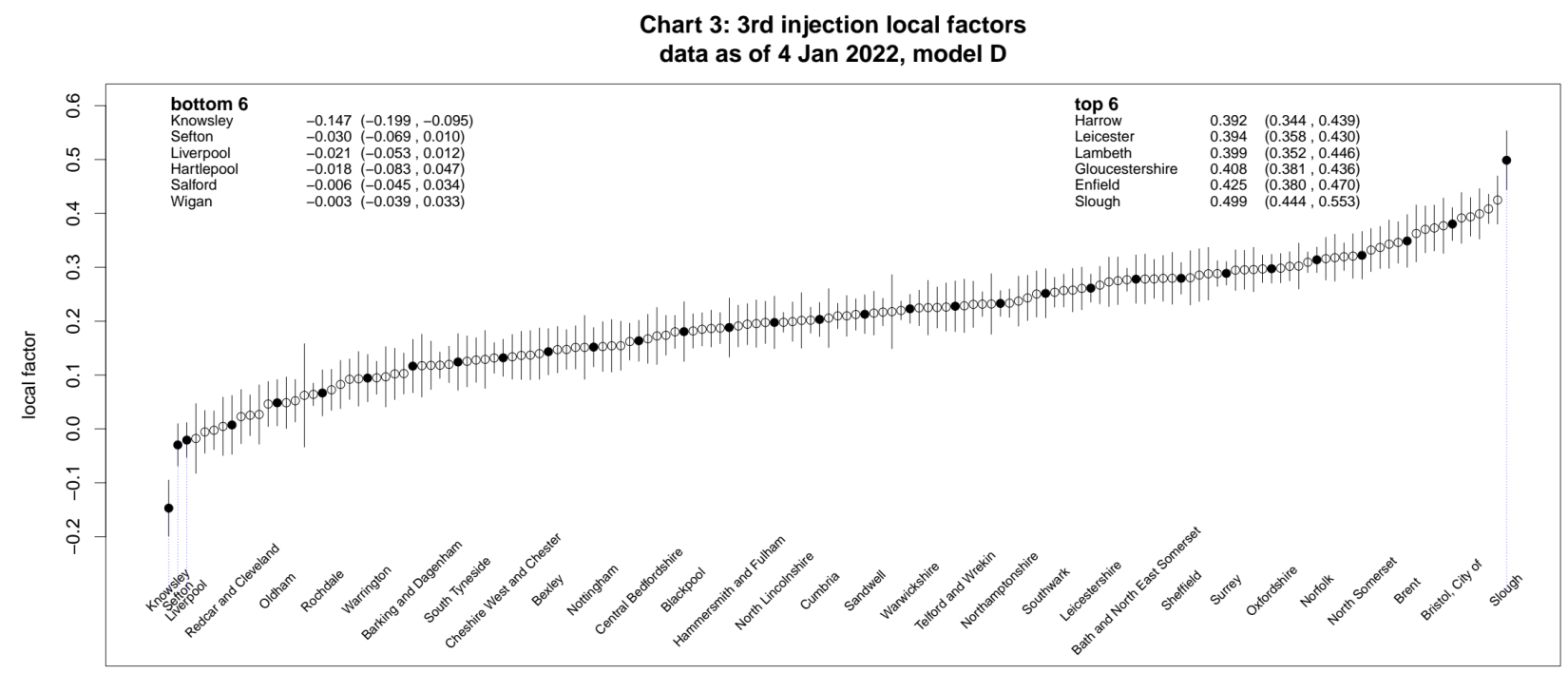

Upper Tier Local Authority

Chart 4 shows the parameter estimates and 90\% credible intervals from second stage modelling of the scaled estimated random effects from model $\mathcal{D}$ for the $3^{\text {rd }}$ injection.

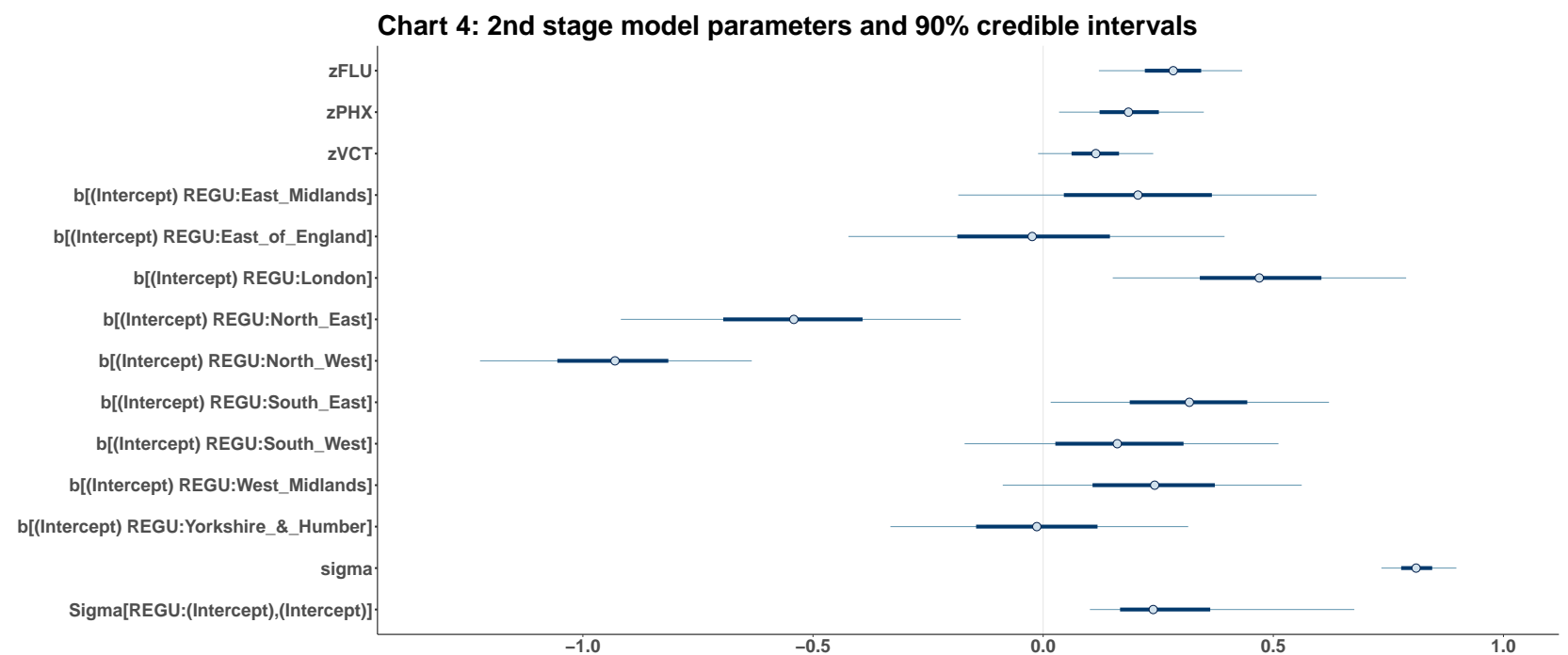

Table 2 shows the parameter estimates and 90\% credible intervals after simulating (x100) the random effects from all four models (applied to the $3^{\text {rd }}$ Injection) before second stage modelling. The second stage model fits increasingly well as the first stage model improves.

Table 2: parameter estimates from $2^{\text {nd }}$ stage modelling of simulated random effects

\begin{tabular}{|c|c|c|c|c|c|c|c|c|}
\hline & $\mathcal{A}$ & & $\mathcal{B}$ & & $\mathcal{C}$ & & $\mathcal{D}$ & \\
\hline Bayes $\mathrm{R}^{2}$ & 0.174 & & 0.270 & & 0.336 & & 0.354 & \\
\hline & estimate & $90 \%$ credible & estimate & $90 \%$ credible & estimate & $90 \%$ credible & estimate & $90 \%$ credible \\
\hline Flu vaccination & 0.217 & $(0.046,0.386)$ & 0.219 & $(0.049,0.390)$ & 0.302 & $(0.142,0.461)$ & 280 & \\
\hline Public Health & 0.292 & $(0.117,0.464)$ & 0.199 & $(0.025,0.370)$ & 0.278 & $(0.115,0.439)$ & 0.191 & $(0.026,0.356)$ \\
\hline accination Centres & 0.123 & $(-0.016,0.263)$ & 0.103 & $(-0.033,0.238)$ & 0.149 & $(0.020,0.278)$ & 0.109 & $(-0.02$ \\
\hline East Midlands & 0.114 & $(-0.202,0.486)$ & 0.217 & $(-0.182,0.63$ & 0.215 & $(-0.168,0.611)$ & 0.203 & \\
\hline East of England & -0.217 & $(-0.65$ & -0.110 & $(-0.5$ & -0.076 & $(-0$. & -0.007 & \\
\hline London & 0.127 & $(-0.14$ & 0.397 & & & $(-0.6$ & & \\
\hline North East & 0.039 & $(-0.27$ & -0.362 & $(-0.76$ & -0.324 & $(-0.7$ & -0.538 & \\
\hline North West & -0.356 & $(-0.713,-0.012)$ & -0.742 & $(-1.072,-0.407)$ & -0.790 & $(-1.103,-0.471)$ & -0.905 & $(-1.2$ \\
\hline South East & -0.051 & $(-0.338,0.218)$ & 0.161 & $(-0.153,0.479)$ & 0.242 & $(-0.058,0.547)$ & 0.307 & $(0.000,0.61)$ \\
\hline South West & 0.069 & $(-0.222,0.388)$ & -0.002 & $(-0.355,0.349)$ & 0.219 & $(-0.116,0.564)$ & 0.160 & $(-0.188,0.511$ \\
\hline West Midlands & 0.196 & $(-0.090,0.551)$ & 0.279 & $(-0.067,0.637)$ & 0.210 & $(-0.119,0.545)$ & 0.233 & $(-0.105,0.575$ \\
\hline Yorkshire \& Humber & 0.122 & $(-0.155,0.446)$ & 0.088 & $(-0.250,0.427)$ & 0.062 & $(-0.262,0.386)$ & -0.011 & $(-0.345,0.32$ \\
\hline
\end{tabular}


medRxiv preprint doi: https://doi.org/10.1101/2022.02.01.22270236; this version posted February 1 , 2022. The copyright holder for this preprint (which was not certified by peer review) is the author/funder, who has granted medRxiv a license to display the preprint in

It is made available under a CC-BY-NC 4.0 International license .

Bayes $\mathrm{R}^{2}$ improves when second stage modelling is applied to the random effects obtained from better first stage models ( $\mathcal{D}$ is preferred to other models by ML value and leads to higher Bayes $\mathrm{R}^{2}$ ). All four models lead to $2^{\text {nd }}$ stage models which show significant elevation (90\% credible interval) for Flu vaccination and the rise in Public Health budgets as predictors of the simulated random effects, whilst the number of Vaccination Centres is only significant if the random effects are simulated from model $\mathcal{C}$. North West Region is a significant negative predictor with all four models, and the North East is significant negative with model $\mathcal{D}$. London is a significant positive predictor of random effects from models $\mathcal{B}$ and $\mathcal{D}$. The South East is borderline positive with model $\mathcal{D}$ only.

A comparable table for the $1^{\text {st }}$ dose shows that Bayes $\mathrm{R}^{2}$ rises from 0.361 for modelling the estimated random effects from $\mathcal{A}$, to 0.442 for $\mathcal{B}, 0.594$ for $\mathcal{C}$, and 0.593 for $\mathcal{D}$. All four models lead to $2^{\text {nd }}$ stage models which show significant elevation (90\% credible interval) for Flu vaccination and the rise in Public Health budgets as predictors of the simulated random effects, and likewise for London and South East regions, whilst North West is negative, and North East is negative for $\mathcal{B}, \mathcal{C}$, and $\mathcal{D}$. South West is positive for $\mathcal{C}$ and $\mathcal{D}$.

For the $2^{\text {nd }}$ dose, Bayes $\mathrm{R}^{2}$ rises from 0.376 for modelling the estimated random effects from $\mathcal{A}$, to 0.447 for $\mathcal{B}, 0.586$ for $\mathcal{C}$, and 0.587 for $\mathcal{D}$. All four models lead to $2^{\text {nd }}$ stage models which show significant elevation (90\% credible interval) for Flu vaccination and the rise in Public Health budgets as predictors of the simulated random effects, and likewise for London and South East regions, whilst North West is negative, and North East is negative for $\mathcal{B}, \mathcal{C}$, and $\mathcal{D}$. South West is positive for $\mathcal{C}$ and $\mathcal{D}$, and borderline for $\mathcal{A}$.

Chart 5 shows the scaled estimated random effects from model $\mathcal{D}$ against the prediction from second stage modelling, for each dose.

Chart 5: $2^{\text {nd }}$ stage prediction of scaled estimated random effects from model $\mathcal{D}$
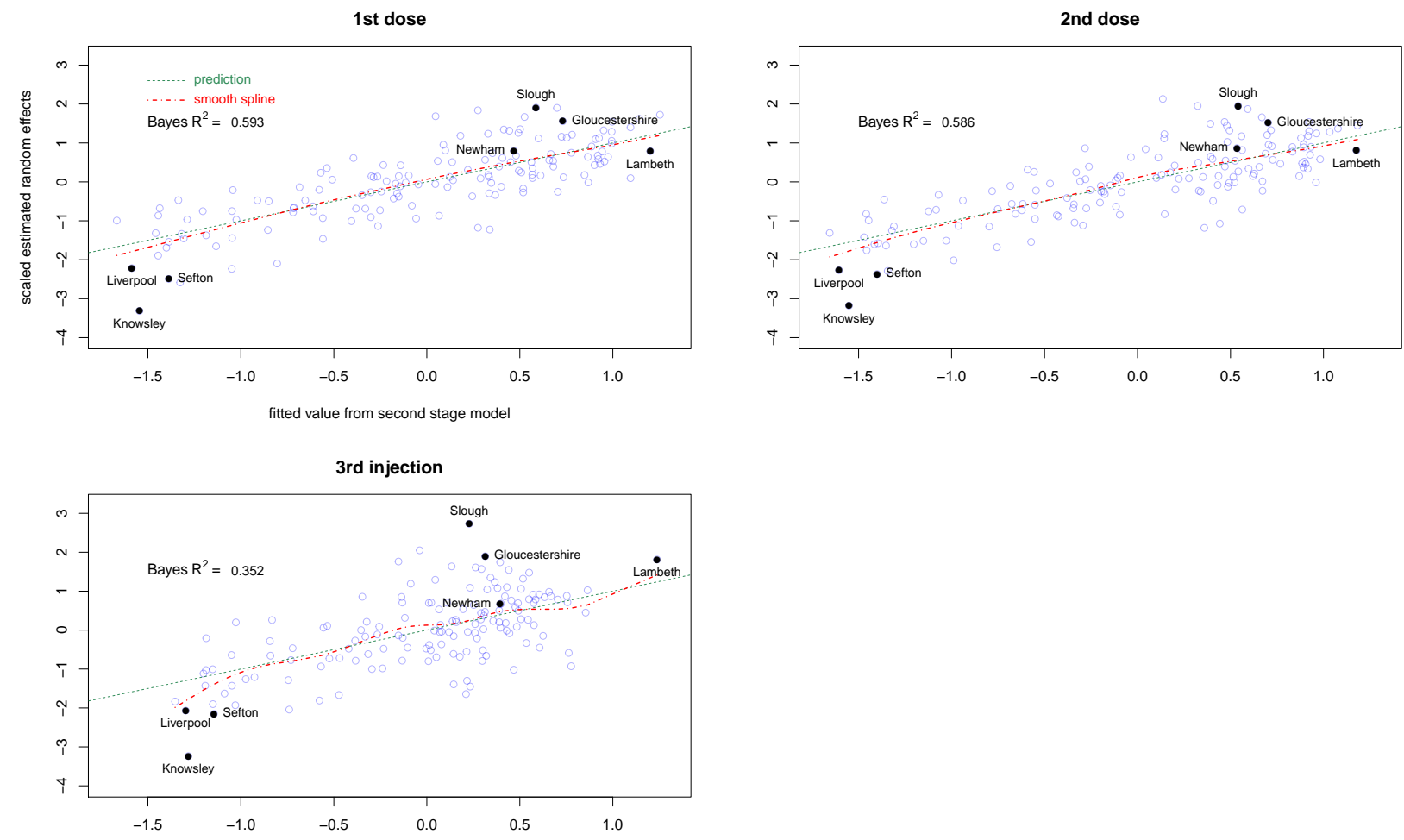
medRxiv preprint doi: https://doi.org/10.1101/2022.02.01.22270236; this version posted February 1, 2022. The copyright holder for this preprint (which was not certified by peer review) is the author/funder, who has granted medRxiv a license to display the preprint in

It is made available under a CC-BY-NC 4.0 International license .

\section{Discussion}

There is extensive literature on Covid-19 vaccine uptake. Before the vaccines were deployed, a telephone and web survey of attitudes, considered by the government's advisory group SAGE in December 2020 (see [4]) found "marked differences existed by ethnicity, with Black ethnic groups the most likely to be COVID-19 vaccine hesitant followed by the Pakistani/Bangladeshi group. Other White ethnic groups (which includes Eastern European communities) also had higher levels of COVID-19 vaccine hesitancy than White UK/White Irish ethnicity”. SAGE cited previous studies to conclude "Barriers to vaccine uptake include perception of risk, low confidence in the vaccine, distrust, access barriers, inconvenience, socio-demographic context and lack of endorsement, lack of vaccine offer or lack of communication from trusted providers and community leaders.”

Later, a meta-analysis of international studies by Qiang Wang (see [3]) found that "Gender, educational level, influenza vaccination history, and trust in the government were strong predictors of COVID-19 vaccination willingness" and that healthworkers were less willing than the general public. A literature review of UK studies by Atiya Kamal (see [5]) concluded "Ethnic minority status was associated with higher vaccine hesitancy and lower vaccine uptake compared with White British groups. Barriers included pre-existing mistrust of formal services, lack of information about the vaccine's safety, misinformation, inaccessible communications, and logistical issues”. A strategy to overcome vaccine hesitancy was advocated by Mohammed S Razai (see [8]), highlighting Confidence (importance, safety and efficacy of vaccines); Complacency (perception of low risk and low disease severity); Convenience (access issues dependent on the context, time and specific vaccine being offered); Communications (sources of information); and Context (sociodemographic characteristics). In an article entitled "What must be done to tackle vaccine hesitancy and barriers to COVID-19 vaccination in migrants?” (see [9]) Alison Crawshaw highlighted "mistrust of the state and health system, stemming from historical events, data sharing policies and dissatisfaction with the initial handling of the pandemic" and advocated "engaging with communities to understand their concerns or barriers to vaccination and working together to co-develop tailored approaches to encourage uptake and rebuild trust”.

A cohort analysis by Helen Curtis et al. (see [7]) of 57.9 million patients' primary care records, concerns the period from 8 December 2020 to 17 March 2021. Of patients aged $\geq 80$ years not in a care home (JCVI group 2) 94.7\% received a vaccine, but with substantial variation by ethnicity (White 96.2\%, Black 68.3\%) and deprivation (least deprived 96.6\%, most deprived 90.7\%). Patients with pre-existing medical conditions were more likely to be vaccinated with two exceptions: severe mental illness (89.5\%) and learning disability (91.4\%).

The Office for National Statistics Coronavirus (COVID-19) latest insights: Vaccines, (as of 28 January 2022) ${ }^{32}$ shows survey data on the proportion receiving 3 vaccinations by occupation groupings, ranging from $80.4 \%$ (Health) to $48.0 \%$ (Elementary trades and related occupations); and for more specific occupations; and by ethnicity, ranging from $68.4 \%$ (White British) to 33.9\% (Black Caribbean).

An ONS technical article ${ }^{33}$ explains the logistic regression models applied to vaccination status of individuals, controlling for sex, ethnicity, age, geographical region, urban or rural classification of their address, deprivation percentile, household size, whether the household was multigenerational. The model outputs ${ }^{34}$ include regional variation, with negative impact of residence in the North West amongst persons aged $18-34$. 
medRxiv preprint doi: https://doi.org/10.1101/2022.02.01.22270236; this version posted February 1, 2022. The copyright holder for this preprint (which was not certified by peer review) is the author/funder, who has granted medRxiv a license to display the preprint in

It is made available under a CC-BY-NC 4.0 International license .

An ONS study of ethnic contrasts in coronavirus death rates published on 26 January $2022{ }^{35}$ found that "Location, measures of disadvantage, occupation, living arrangements, pre-existing health conditions and vaccination status accounted for a large proportion of the excess rate of death involving COVID-19 in most ethnic minority groups; however, the Bangladeshi ethnic group and men from the Pakistani ethnic group remained at higher risk than White British people in the third wave, even after adjusting for vaccination status”.

A 2018 study of childhood immunisation rates in Italy by Veronica Toffolutti ${ }^{36}$, found that reductions in public health budgets were a significant predictor of falling immunisation rates.

In the geographical analysis reported here, I initially sought to learn whether the current very low booster uptake in particular small areas was unexpected, or could be predicted from the national data on the UK Coronavirus Dashboard, at Middle Super Output level.

In each MSOA, the data shows the number of people eligible for the vaccine, and the cumulative number actually vaccinated with the first and second doses, and the $3^{\text {rd }}$ Injection. The latter covers both people receiving the booster, and those with compromised immunity who were given a $3^{\text {rd }}$ primary dose. The ratio of those vaccinated to those eligible, is the uptake. But the actual numbers vaccinated and eligible give more information, and can be modelled as a binomial variable.

The Generalized Additive Model, implemented in R with the mgcv package, is an established technique for non-linear modelling. The variance in this data exceeds what would be expected for a binomial variable, but can be estimated by relaxing the "binomial" assumption to "quasibinomial". Using demographic, employment and local health data as predictors, such models fit this data well.

The models are improved by including a random effect assigned to the Upper Tier Local Authority within which the MSOA is found, allowing other aspects of the UTLA to influence the prediction.

Four different models for each of the three vaccinations, all gave a good fit to the data, with the proportion of deviance explained ranging from $95.4 \%$ to $97.2 \%$. Chart 1 shows how well the preferred model $\mathcal{D}$ performs for the $3^{\text {rd }}$ injection. This close fit means that the observed values in a particular MSOA are almost always near the prediction from the national data.

The covariate structure was simplified to enable models to be computable on a PC. For example, whilst population data is available for each year of age, the models use broader categories such as aged 15-24 or $25-44$. Even so, $\mathcal{D}$ has 33 smoothers, each with a smoothing parameter which must be estimated during fitting, along with 341 coefficients.

The smoothers for $\mathcal{D}$, some of which are shown in Chart 2, show the effect of individual covariates in the context of all others in the model. The most powerful predictors are the Index of Multiple Deprivation, the population proportions aged 15-24, aged 25-44, of Other White ethnicity, South Asian (Indian, Pakistani and Bangladeshi combined), and the combined group of African, Caribbean, Other Black, and Other ethnicity.

The negative slope of the first smoother means that a higher IMD leads to a lower predicted uptake if all other variables are unchanged. Education Deprivation (a specific domain within the overall index IMD) also has a negative slope, although its effect is smaller (shown on Chart 2 with "narrow scale”). All six most powerful predictors have smoothers with negative slope. The dependence on age is to be expected, as the vaccine rollout targeted different age groups at different times. 
medRxiv preprint doi: https://doi.org/10.1101/2022.02.01.22270236; this version posted February 1, 2022. The copyright holder for this preprint (which was not certified by peer review) is the author/funder, who has granted medRxiv a license to display the preprint in

It is made available under a CC-BY-NC 4.0 International license.

Ethnicity has significant impact on uptake, as many other studies have found. The smoother for the "Other White" group has the widest range, comparable to that for IMD, showing that the "Other White” proportion of the population has a strong impact on predicted uptake.

Several other smoothers have small positive slope, such as those for employment in Public Adminstration, or Health and Social Care. The latter indicates that despite the well publicised vaccine hesitancy amongst a minority of NHS and care staff, the overall impact of employment in these sectors is to increase the uptake of the $3^{\text {rd }}$ Injection. This is consistent with the ONS data (see [32]). For the $1^{\text {st }}$ and $2^{\text {nd }}$ doses, the increase is clear only when the proportion of Health and Care staff exceeds the $20^{\text {th }}$ percentile of this covariate.

The smoother for average distance to A\&E also has a positive slope, suggesting that people living further from an emergency department may be more concerned to take the vaccination. Likewise, increasing Health Deprivation is associated with increasing uptake. Conversely, increased GP registration is associated with decreasing uptake. However, there is some uncertainty in the GP registration data, and NHS Digital have commented on the excess of GP registrations over ONS population estimates. ${ }^{37}$

Fitting any of these models gives estimates for the effect of each of the demographic, employment, and health variables included as predictors, and the estimated "random effect" of each of the 149 UTLA. For example "Knowsley" has a strong negative impact, and "Slough" has a strong positive impact. These effects are not to be confused with the actual uptake of vaccination in the local authority, which may be low or high due to deprivation or other fixed effects, and which may vary widely amongst MSOAs within the local authority. Uptake of the $3^{\text {rd }}$ Injection varied from $32.2 \%$ to $57.6 \%$ within Knowsley, from $17.3 \%$ to $65.5 \%$ in Liverpool, and from $36.9 \%$ to $75.8 \%$ in Sefton.

The random effect alters the prediction from the fixed effects alone. If Beckton Park (in Newham) had been located in Slough with identical demography, employment, and health indicators, the predicted uptake of the $3^{\text {rd }}$ Injection would rise by $18 \%$, whilst if it were in Knowsley the prediction would fall by $29 \%$.

The range in magnitude of the random effects is comparable to that of ethnicity groups. On the scale of the linear predictor, the smoothers for Other White, South Asian, and Afro-Caribbean groups range from 0.09 to $-0.70,0.05$ to -0.42 , and 0.07 to -0.49 respectively, each smoother descending as the ethnicity proportion rises. The random effects range from - 0.15 (Knowsley) to 0.50 (Slough). The difference between the random effects for Knowsley and Slough is greater than the maximal difference between any two MSOA due to the population proportion of South Asian or AfroCaribbean ethnicity, and only slightly less than the maximal difference due to the proportion of Other White.

The second stage of modelling focused on the 149 random effects, seeking to explain their estimated values in terms of other information at UTLA level. This stage tested the impact of flu vaccination rates, public health budgets, vaccination centres, and Region, treated as a random factor. Ideally all of the UTLA and MSOA level variables would be incorporated in a single model. But that appeared prohibitively slow to compute, so the random effects estimates from the first stage mgcv modelling were considered as observations, to be modelled in their own right. Simulated random effects generated from the first stage model were used to refine the parameter estimates and credible intervals from the second stage, but this made little difference. For example the parameters and credible intervals for model $\mathcal{D}$ in Chart 4 are similar to those found for $\mathcal{D}$ after simulation in Table 2. 
medRxiv preprint doi: https://doi.org/10.1101/2022.02.01.22270236; this version posted February 1, 2022. The copyright holder for this preprint (which was not certified by peer review) is the author/funder, who has granted medRxiv a license to display the preprint in It is made available under a CC-BY-NC 4.0 International license .

The second stage model passes Bayesian checks and shows clear effects of Region, flu vaccination, and public health budget increase. Chart 5 shows the extent to which the chosen predictors actually explain the estimated random effects. None of the points are outliers (by pareto_k) and the model fits well for the $1^{\text {st }}$ and $2^{\text {nd }}$ doses with Bayes $\mathrm{R}^{2} \sim 0.6$. The lower value for the $3^{\text {rd }}$ injection, $\sim 0.35$, suggests that there may be other relevant covariates at UTLA level.

It is striking that Knowsley, Liverpool and Sefton all appear at the lower left of Chart 5 and Knowsley is conspicuously low for all three vaccinations. The Merseyside local authorities are amongst the most deprived in England, but IMD already appears in the first stage model $\mathcal{D}$ as a fixed effect so was not expected to have any impact on the second stage model. Indeed, if IMD is averaged over the MSOA within each UTLA and then used as a predictor in second stage modelling, it has no significant effect.

Simply being in the North West is the most powerful predictor of low uptake in this model, and in addition Knowsley had the $13^{\text {th }}$ lowest increase in public health funding (and the $3^{\text {rd }}$ lowest within the North West), rising by only $0.88 \%$. Newham benefits from being in London and from the larger increase in its public health budget (rising by 2.09\%), and possibly from the vaccination centre located in Olympic Park, an outlier with positive residual (see Chart 1). Flu vaccination rates are higher in Knowsley (49.2) than in Newham (45.5), so cannot explain the disparity in random effects.

Slough benefits from being in the South East and possibly from a vaccination centre, whilst its flu vaccination rate and rise in public health budget are both close to their respective mean values. However the random effects for Slough also exceed prediction. The highest predicted value is in Lambeth, where the flu vaccination rate is below average, but which benefits from being in London with a $4.88 \%$ rise in public health budget and 3 vaccination centres. Its estimated random effect is close to prediction for all 3 doses.

All such conclusions depend on the validity of the models. The first stage MSOA level modelling fits very well, and the resulting estimated random effects from all four models are highly correlated. That is, the random effects are not simply artefacts of the model, once ethnicity is included. The estimated random effects change dramatically if ethnicity is omitted from the model.

The UTLA level effects could be described as a postcode lottery, as they are not explained by the population characteristics controlled for in the fixed effects, but are associated with other geographical factors. However, a "lottery" suggests pure chance whereas economic policy decisions affect Regional disparity and public health budgets, which in turn affect Covid vaccination rates.

Much of the literature has focused on "vaccine hesitancy" of specific population subgroups. The modelling here confirms the impact of ethnicity along with deprivation and age, but also identifies additional factors, characteristic of the locality rather than the population living in it, consistent with evidence on childhood immunisations in Italy.

These models indicate that whatever other barriers exist due to deprivation and within particular ethnicities, the annual change in local authority public health budgets is also a significant factor. Therefore, increasing local public health allocations would be one simple way to improve Covid vaccine uptake. 
medRxiv preprint doi: https://doi.org/10.1101/2022.02.01.22270236; this version posted February 1, 2022. The copyright holder for this preprint (which was not certified by peer review) is the author/funder, who has granted medRxiv a license to display the preprint in It is made available under a CC-BY-NC 4.0 International license.

\section{Acknowledgements}

Thanks to David Taylor Robinson for helpful comments including the AHAH dataset and the suggestion that budgets could be a predictor, and to Isabelle Whelan for an unpublished essay “Austerity, NHS reform and vaccine uptake”, written before the pandemic. 
medRxiv preprint doi: https://doi.org/10.1101/2022.02.01.22270236; this version posted February 1 , 2022. The copyright holder for this preprint (which was not certified by peer review) is the author/funder, who has granted medRxiv a license to display the preprint in It is made available under a CC-BY-NC 4.0 International license .

\section{References}

1 NHS begins COVID-19 booster vaccination campaign. NHS England. 16 September 2021. https://www.england.nhs.uk/2021/09/nhs-begins-covid-19-booster-vaccination-campaign/

2 GOV.UK Coronavirus (COVID-19) in the UK https://coronavirus.data.gov.uk/details/vaccinations

3 Vaccination against COVID-19: A systematic review and meta-analysis of acceptability and its predictors. Qiang Wang, Liuqing Yang, Hui Jin, Leesa Lin. Preventive Medicine Volume 150, September 2021, 106694 https://doi.org/10.1016/j.ypmed.2021.106694

4 Factors influencing COVID-19 vaccine uptake among minority ethnic groups Ethnicity sub-group of the Scientific Advisory Group for Emergencies (SAGE). 17 December 2020 https://assets.publishing.service.gov.uk/government/uploads/system/uploads/attachment data/file/952716/s0979factors-influencing-vaccine-uptake-minority-ethnic-groups.pdf

5 A Rapid Systematic Review of Factors Influencing COVID-19 Vaccination Uptake in Minority Ethnic Groups in the UK. Atiya Kamal, Ava Hodson, Julia M. Pearce. Vaccines 2021, 9(10), 1121; https://doi.org/10.3390/vaccines9101121

6 Factors affecting COVID-19 vaccination acceptance and uptake among the general public: a living behavioural science evidence synthesis (v1.0, Apr 30th, 2021). Jacob Crawshaw, Kristin Konnyu, Gisell Castillo, Zack van Allen, Jeremy Grimshaw, Justin Presseau. https://www.mcmasterforum.org/docs/default-source/product-documents/living-evidence-syntheses/covid-19living-evidence-synthesis-4.1---factors-affecting-covid-19-vaccination-acceptance-and-uptake-among-the-generalpublic.pdf?sfvrsn $=5368712 \mathrm{f} 7$

7 Trends and clinical characteristics of COVID-19 vaccine recipients: a federated analysis of 57.9 million patients' primary care records in situ using OpenSAFELY. Helen J Curtis, Peter Inglesby, Caroline E Morton, Brian MacKenna, Amelia Green, William Hulme, Alex J Walker et al. British Journal of General Practice 2022; 72 (714): e51-e62. DOI: https://doi.org/10.3399/BJGP.2021.0376

8 COVID-19 vaccine hesitancy: the five Cs to tackle behavioural and sociodemographic factors. Mohammad S Razai, Pippa Oakeshott, Aneez Esmail, Charles Shey Wiysonge, Kasisomayajula Viswanath, Melinda C Mills. Journal of the Royal Society of Medicine. Volume: 114 issue: 6, page(s): 295-298. Article first published online: June 2, 2021; Issue published: June 1, 2021 https://journals.sagepub.com/doi/full/10.1177/01410768211018951

9 What must be done to tackle vaccine hesitancy and barriers to COVID-19 vaccination in migrants? Alison F Crawshaw, Anna Deal, Kieran Rustage, Alice S Forster, Ines Campos-Matos, Tushna Vandrevala, Andrea Würz et al. Journal of Travel Medicine, Volume 28, Issue 4, May 2021, Published: 26 March 2021 https://doi.org/10.1093/jtm/taab048

10 GOV.UK Coronavirus (COVID-19) in the UK. Download data. https://coronavirus.data.gov.uk/details/download

11 English indices of deprivation 2019. Ministry of Housing, Communities \& Local Government. 26 September 2019 https://www.gov.uk/government/statistics/english-indices-of-deprivation-2019

12 Lower layer Super Output Area population density (National Statistics). Mid-2019 SAPE22DT11 edition. Office for National Statistics. https://www.ons.gov.uk/file?uri=\%2fpeoplepopulationandcommunity\%2fpopulationandmigration \%2fpopulationestimates\%2fdatasets\%2flowersuperoutputareapopulationdensity\%2fmid2019sape22dt11/ sape22dt11mid2019lsoapopulationdensity.zip

13 Middle Super Output Area population estimates (supporting information).

Office for National Statistics https:/www.ons.gov.uk/peoplepopulationandcommunity/populationandmigration/populationestimates/datasets/ middlesuperoutputareamidyearpopulationestimates 
medRxiv preprint doi: https://doi.org/10.1101/2022.02.01.22270236; this version posted February 1 , 2022. The copyright holder for this preprint (which was not certified by peer review) is the author/funder, who has granted medRxiv a license to display the preprint in

It is made available under a CC-BY-NC 4.0 International license .

14 Ethnic group by sex by age. DC2101EW. Census 2011

NOMIS official labour market statistics.

https://www.nomisweb.co.uk/census/2011/dc2101ew

15 Industry by sex by age. DC6110EW. Census 2011

NOMIS official labour market statistics.

https://www.nomisweb.co.uk/census/2011/dc6110ew

16 QS421EW - Communal establishment management and type - People

NOMIS official labour market statistics.

https://www.nomisweb.co.uk/query/553.1/advanced.aspx

17 DC1109EW - Household composition by age by sex

NOMIS official labour market statistics.

https://www.nomisweb.co.uk/query/748.1/advanced.aspx

18 Access to Healthy Assets \& Hazards (AHAH)

Consumer Data Research Center. 1 July 2019

https://data.cdrc.ac.uk/dataset/access-healthy-assets-hazards-ahah

19 Patients Registered at a GP Practice July 2020. NHS Digital

https://digital.nhs.uk/data-and-information/publications/statistical/patients-registered-at-a-gp-practice/july-2020

20 https://coronavirus.data.gov.uk/downloads/msoa data/MSOAs latest.xlsx

21 Seasonal influenza vaccine uptake amongst GP Patients in England. End of season data for 1 September 2020 to 28 February 2021. Public Health England

https://assets.publishing.service.gov.uk/government/uploads/system/uploads/attachment data/file/995899/

Supplementarytables LA 2021.ods

22 List of vaccination sites. Vaccination sites as of 17 November 2021. NHS England.

https://www.england.nhs.uk/coronavirus/hospital-hubs-and-local-vaccination-services/

23 National Statistics Postcode Lookup (November 2020). Office for National Statistics https://geoportal.statistics.gov.uk/datasets/4df8a1a188e74542aebee164525d7ca9/about

24 Public health ring-fenced grant 2021 to 2022: local authority circular. 16 March 2021. Department of Health and Social Care. https://www.gov.uk/government/publications/public-health-grants-to-local-authorities-2021-to-2022/ public-health-ring-fenced-grant-2021-to-2022-local-authority-circular;

PUBLIC HEALTH RING-FENCED GRANT 2020/21. Local Authority Circular LAC(DHSC)(2020) 2. Published March 2020 https://assets.publishing.service.gov.uk/government/uploads/system/uploads/attachment data/file/ 872798/DHSC allocations circular 2020 to 2021.pdf

25 mgcv: Mixed GAM Computation Vehicle with Automatic Smoothness Estimation Simon Wood https://CRAN.R-project.org/package=mgcV

26 Wood, S.N. (2017) Generalized Additive Models: An Introduction with R (2nd edition). Chapman \& Hall/ CRC, Boca Raton, Florida

27 Wood, S.N., N. Pya and B. Saefken (2016), Smoothing parameter and model selection for general smooth models. Journal of the American Statistical Association 111, 1548-1575 https://doi.org/10.1080/01621459.2016.1180986

28 Goodrich B, Gabry J, Ali I \& Brilleman S. (2020). rstanarm: Bayesian applied regression modeling via Stan. R package version 2.21.1 http://mc-stan.org/rstanarm/

29 loo: Efficient leave-one-out cross-validation and WAIC for Bayesian models Aki Vehtari, Jonah Gabry, Mans Magnusson, Yuling Yao, Paul-Christian Bürkner, Topi Paananen, Andrew Gelman 2020, http://mc-stan.org/loo/index.html 
medRxiv preprint doi: https://doi.org/10.1101/2022.02.01.22270236; this version posted February 1, 2022. The copyright holder for this preprint (which was not certified by peer review) is the author/funder, who has granted medRxiv a license to display the preprint in It is made available under a CC-BY-NC 4.0 International license .

30 LOO package glossary http://mc-stan.org/loo/reference/loo-glossary.html

31 Compute a Bayesian version of R-squared or LOO-adjusted R-squared for regression models https://mc-stan.org/rstanarm/reference/bayes R2.stanreg.html

32 Coronavirus (COVID-19) latest insights: Vaccines. 28 January 2022. Office for National Statistics. https://www.ons.gov.uk/peoplepopulationandcommunity/healthandsocialcare/conditionsanddiseases/articles/ coronaviruscovid19latestinsights/vaccines

33 Coronavirus (COVID-19) Infection Survey technical article: Analysis of characteristics associated with vaccination uptake. Office for National Statistics. Kara Steel, Philippa Haughton and Joel Jones. 15 November 2021 https://www.ons.gov.uk/peoplepopulationandcommunity/healthandsocialcare/conditionsanddiseases/articles/ coronaviruscovid19infectionsurveytechnicalarticleanalysisofcharacteristicsassociatedwithvaccinationuptake/2021$\underline{11-15}$

34 Coronavirus (COVID-19) Infection Survey technical article: analysis of characteristics associated with vaccination uptake. 15 November edition of this dataset. Office for National Statistics. Kara Steel, Philippa Haughton and Joel Jones https://www.ons.gov.uk/peoplepopulationandcommunity/healthandsocialcare/conditionsanddiseases/datasets/ coronaviruscovid19infectionsurveytechnicalarticleanalysisofcharacteristicsassociatedwithvaccinationuptake

35 Updating ethnic contrasts in deaths involving the coronavirus (COVID-19), England: 8 December 2020 to 1 December 2021. Office for National Statistics. 26 January 2022. Tamanna Ahmed, Rose Drummond, Matt Bosworth https://www.ons.gov.uk/peoplepopulationandcommunity/birthsdeathsandmarriages/deaths/articles/ updatingethniccontrastsindeathsinvolvingthecoronaviruscovid19englandandwales/ 8december2020to1december2021

36 Toffolutti V, McKee M, Melegaro A, Ricciardi W, Stuckler D. Austerity, measles and mandatory vaccination: crossregional analysis of vaccination in Italy 2000-14. Eur J Public Health. 2018;29(1):123-127. doi:10.1093/eurpub/cky178 https://academic.oup.com/eurpub/article/29/1/123/5090999

37 Patients Registered at a GP Practice April 2021. NHS Digital. 15 April 2021 https://digital.nhs.uk/data-and-information/publications/statistical/patients-registered-at-a-gp-practice/april-2021/ spotlight-report-april-2021 